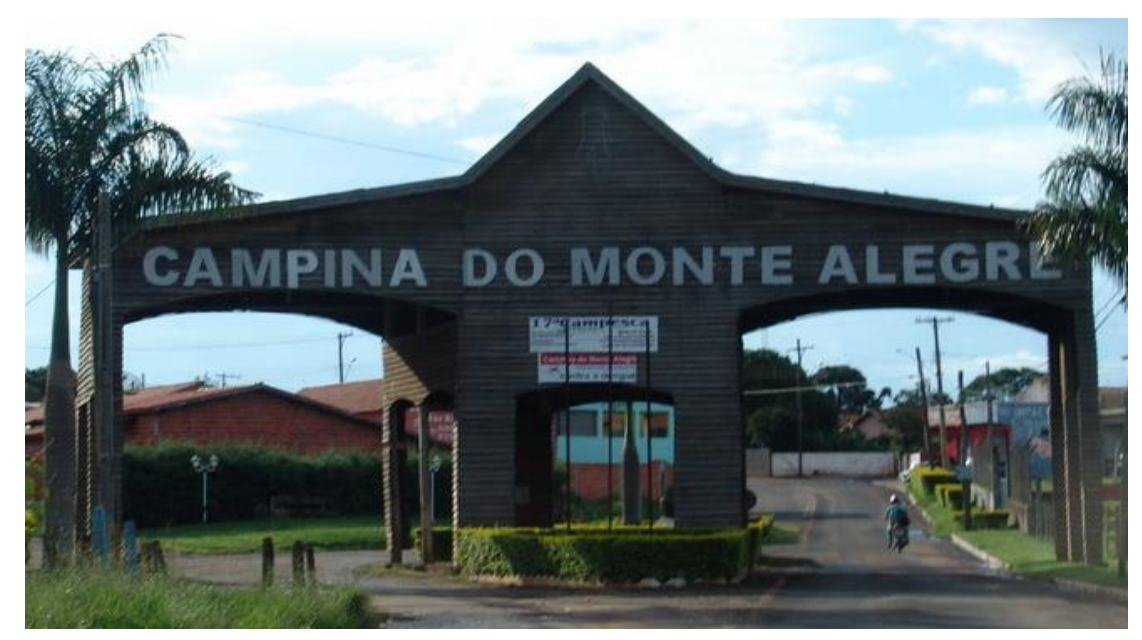

\title{
Relações entre sujeitos em Campina do Monte Alegre após a implantação da UFSCarı
}

\author{
Relations betwween subjects in Campina do Monte Alegre \\ after the implementation of UFSCar
}

\author{
Ilka de Oliveira Mota2 \\ https://orcid.org/0000-0001-6637-4310
}

Resumo: Apoiado na Análise de Discurso de cunho materialista na interface com autores como Freud e Derrida, este artigo contribui com os estudos sobre as relações discursivas engendradas no espaço da cidade, buscando compreender como antigos e novos moradores representam a cidade a partir da implantação da UFSCar Lagoa do Sino. Com base no pressuposto de que a cidade é um lugar material no qual processos discursivos são produzidos, formula-se a hipótese de que, de um lado, há uma divisão imaginária entre cidade e seus antigos habitantes e, de outro, universidade e novos moradores, resultando em gestos de hostilidade e repulsa entre os sujeitos. O corpus é constituído de quatro entrevistas feitas com dois moradores antigos e dois recémmoradores. Como resultado, apesar de existir uma tentativa de segregação, há brechas para possíveis mudanças de posição, o que permite um espaço de convívio e de relações entre eu-outro na cidade.

Palavras-chave: Cidade; Estabelecidos; Outsiders; UFSCar; Sociabilidade.

Abstract: Based on a materialistic Discourse Analysis in the interface with authors such as Freud and Derrida, this article aims to contribute to studies on the discursive relations engendered in the city, seeking to understand how established and new residents represent the city from the implantation of UFSCar Lagoa do Sino. The assumption is that the city is a material place in which discursive processes (clashes, struggles, empathy etc.) are produced. The hypothesis is that there is an imaginary division between the city and its established inhabitants, on the one hand, and the university and the new residents, on the other, resulting in gestures of hostility and disgust among the subjects. The corpus consists of four interviews done with two established residents and two new residents. The result pointed out that, although there is an attempt at segregation, there are loopholes for possible changes in position, which allows a space for conviviality and relations between the self-other in the city.

Keywords: City; Established; Outsiders. UFSCar; Sociability.

1 Uma parte da pesquisa foi apresentada no IX SEAD/2019, em Pernambuco, e no evento da ABRALIN50, em maio de 2019, na cidade de Maceio, estado de Alagoas.

2 Pós-doutorado em Linguística Aplicada sob a supervisão de Maria José Coracini (2020); doutorado em Linguística Aplicada (2010) e mestrado em Linguística (2004), todos os títulos obtidos pela Universidade Estadual de Campinas (IEL/DLA/DLA/DL, respectivamente). É professora associada I da Universidade Federal de São Carlos, campus Lagoa do Sino. Email: ilkamotaeducacao@gmail.com 


\section{Considerações iniciais}

Ao Raduan Nassar, nosso e-terno visionário uma singela homenagem.

A reflexão que ora apresentamos diz respeito à pesquisa que fizemos, ao nível de pós-doutoramento, no Instituto de Estudos da Linguagem da Universidade Estadual de Campinas, Departamento de Linguística Aplicada3.

O tema do trabalho inscreve-se na área dos estudos da linguagem e vincula-se a uma perspectiva discursiva materialista que tem o discurso como objeto teórico.

O objetivo consistiu em analisar as relações sociais e discursivas estabelecidas no espaço material da cidade a partir da implantação do campus Lagoa do Sino da Universidade Federal de São Carlos (UFSCar), na cidade de Buri4. Para isso, como já sinalizamos, apoiamo-nos nos estudos do discurso de cunho materialista estabelecendo, ao mesmo tempo, uma interface com as reflexões promovidas pela Psicanálise e Desconstrução.

Para explicitar as motivações que nos levaram a escolher o aludido tema de pesquisa, tentaremos, nos próximos parágrafos, fazer uma síntese das condições de produção de existência da cidade, a fim de que o leitor compreenda as nuances de seu contexto material. Na sequência, explicitaremos a hipótese de trabalho, as perguntas e os objetivos que o norteiam.

Depois de mais de 35 anos, retorno à cidade de Campina do Monte Alegre (CMA doravante), localizada no sudoeste paulista, não mais como uma criança para nos banhar (meus irmãos e eu) no lago de Campininha (no diminutivo, como é conhecida por seus moradores), mas, desta vez, como docente de uma universidade pública federals.

Mesmo passados tantos anos, algumas lembranças da cidade irrompem insistentemente nos fios da memória: pacata, poucas casas, uma igreja católica no meio da praça, o lago, poucos habitantes e animais nas ruas (galinhas, cavalos, vacas etc.), o sino da igreja e o cantar do galo. É essa a fotografia mental que tenho de Campininha. Em 2016, volto ao lugar em que passei parte da infância e observo algumas mudanças

\footnotetext{
3 Trata-se de pós-doutorado produzido, sem bolsa e sem afastamento, finalizado em fevereiro de 2020, no Instituto de Estudos da Linguagem.

4 O campus Lagoa do Sino pertence ao território de Buri, no limite com a cidade de Campina do Monte Alegre. Em virtude de o campus estar geograficamente mais próximo de Campina, grande parte dos alunos estabelece nela residência durante os anos de estudo.

5 Campina do Monte Alegre situa-se em uma região conhecida historicamente como ramal da fome. A implantação da Universidade Federal de São Carlos no sudoeste paulista teve e tem por objetivo transformar essa realidade, contribuindo, entre outros, para o desenvolvimento econômico e social dessa e de outras cidades ao entorno. Voltaremos a essa questão mais adiante.
} 
importantes: movimento significativo de pessoas nas ruas, em grande parte jovens universitário(a)s e automóveis; além da igreja da praça somam-se mais meia dúzia de igrejas evangélicas; o lago permaneceu mas para ser contemplado apenas. A presença de animais e a paisagem edílica parecem as mesmas, todavia há uma diferença fundamental: a instalação de uma universidade pública na cidade. Na posição de pesquisadora, meu desafio e curiosidade são compreender sentidos, marcas da subjetividade, traços da memória, ecos da alteridade, ouvir o silêncio que a narrativa dos antigos e novos habitantes podem (ou não) revelar.

A partir de 2016, ano em que passei a ministrar aula na UFSCar, campus Lagoa do Sino, têm chamado a atenção as mudanças pelas quais a cidade de CMA tem passado, principalmente a partir da implantação do campus Lagoa do Sino da UFSCar, em 2014, até o presente momento6. Vale dizer, mudanças não somente relacionadas ao âmbito econômico, mas, fundamentalmente, no que dizem respeito às questões identitárias e às relações discursivas e sociais que irromperam a partir da implantação da referida universidade na cidade.

O campus está localizado em uma fazenda de 643 hectares doada pelo escritor brasileiro Raduan Nassar - daí a nossa homenagem e admiração a ele - com o objetivo de promover o desenvolvimento econômico, social e sustentável da região do sudoeste paulista, uma vez que o Índice de Desenvolvimento Humano (IDH) é o menor do estado de São Paulo (MOTA, PEREIRA e NIERO, 2018) e, contraditoriamente, apresenta um dos PIB (Produto Interno Bruto) mais altos do Estado de São Paulo.

No plano do imaginário, a cidade comparece como um lugar de unidade, completude dos sentidos e dos sujeitos. Da perspectiva discursiva assumida neste trabalho, concebemo-la como um espaço material de significação e, portanto, um produto historicamente construído em condições específicas. Nesse sentido, concordamos com Orlandi (2011, p. 695) quando afirma:

A cidade se materializa em um espaço que é um espaço significativo: nela sujeitos, práticas sociais, relações entre o indivíduo e a sociedade têm uma forma material, resultante da simbolização da relação do espaço, citadino, com os sujeitos que nela existem, transitam, habitam, politicamente significados.

\footnotetext{
6 De acordo com o último Censo (2010), CMA contava com 5567 habitantes, mas, com a chegada da UFSCar, esse número duplicou: habitantes de outras cidades e estados brasileiros (alunos, professores e técnicos administrativos) mudaram para a cidade, incluindo aí povos indígenas dos quatro cantos do país.
} 
Como a universidade faz parte da cidade, ela não é um espaço homogêneo; ela influencia direta e/ou indiretamente as relações subjetivas, históricas e sociais da vida da cidade em que está situada. Noutros termos, a universidade implica, pois, relações subjetivas, sociais e culturais importantes no processo discursivo estabelecido na/a partir da cidade. Nela atravessam vários discursos e circulam diferentes sujeitos, isto é, diferentes formas de ser sujeito no mundo e relações sociais das mais diversas.

Levando em consideração que CMA é uma "cidade do interior", cidade fortemente marcada pela ruralidade e acentuado tradicionalismo em relação à moral e aos bons costumes, as diferentes formas de sujeito histórico que têm entrado e habitado (n)esse espaço (os outsiders) têm produzido efeitos importantes, principalmente com a chegada de estudantes de diferentes lugares do Brasil. A aparição/implantação do campus na cidade de CMA tem promovido um "abalo" nas redes de filiação histórica sedimentadas 7.

Nesse sentido, a cidade vai muito além de ser um espaço físico onde transitam meros corpos biológicos. Concebemo-la como espaço simbólico e político no qual se engendram relações discursivas e sociais por e para sujeitos historicamente constituídos. Sujeito esse que funciona pela ideologia e pelo inconsciente ao mesmo tempo. É nela na materialidade da cidade - em que acontecem e se fazem encontros, laços, circuitos de afetos dos mais diversos (SAFATLE, 2016), que permitem tanto a socialização e convivialidade quanto a segregação e a hostilidade.

Partimos do pressuposto de que o acontecimento, pelo seu efeito de sentido, perturba, desestabiliza não somente a própria memória, mas especialmente as redes e os trajetos de filiações históricas nas quais ele rompe. Assim sendo, formulamos a hipótese de que, compreendida como acontecimento (PECHEUX, 1983), a implantação do campus da UFSCar na cidade de CMA produziu uma divisão imaginária entre cidade e antigos habitantes, de um lado, e universidade e os novos moradores, de outro, resultando em gestos de hostilidade e repulsa entre os sujeitos que habitam CMA. Dito de outro modo, há uma tendência à cisão entre os habitantes antigos da cidade e os novos moradores, o que produz mal-estar (FREUD, 1996 [1929]), estranhamento e tentativa de exclusão da alteridade, do diferente portanto.

7 Por permitir a irrupção do novo, do singular, do estranho, é que entendemos a implantação da UFSCar na cidade de CMA como um acontecimento, compreendido aqui como singularidade, que vem abalar o estabelecido, o naturalizado, capaz de promover deslocamentos no processo de constituição dos sentidos e dos sujeitos (PECHEUX, 1983). 
Com base na hipótese esboçada, formulamos as seguintes perguntas que norteiam o presente estudo, quais segam: i) Como os antigos e os novos habitantes de CMA representam a si mesmo e ao outro em sua relação com a cidade e quais as consequências de tais representações para a constituição das relações sociais e subjetivas entre eles (estabelecidos e outsiders8)? e ii) Qual a natureza das relações sociais e discursivas produzidas entre estabelecidos e outsiders no espaço da cidade?

Em sua totalidade, o corpus foi produzido a partir de entrevistas com antigos e novos moradores, envolvendo 12 habitantes de cada, totalizando 24 . No entanto, em razão do espaço aqui concedido, produzimos quatro recortes de quatro entrevistas feitas com dois moradores estabelecidos e dois moradores outsiders. Voltaremos mais adiante sobre essa questão.

A ideia foi construir um espaço discursivo de escuta, motivado por uma pergunta, qual seja: "Fale-me um pouco sobre a presença da UFSCar na cidade de Campina do Monte Alegre", de modo que os habitantes pudessem relatar (narrar) suas impressões sobre a cidade e os sujeitos que nela circulam na relação com o campus Lagoa do Sino da UFSCar. Pretendeu-se compreender as representações imaginárias que tecem o fio do discurso e seus efeitos de sentido no processo de significação de si e do outro sempre considerando a cidade como carro-chefe desse/nesse processo.

A opção pela entrevista justificou-se pelo fato de permitir a abertura de um lugar enunciativo a partir do qual gestos de interpretação pudessem irromper e revelar processos de (des-)identificação importantes para a compreensão das representações imaginárias em jogo e das relações estabelecidas no espaço material da cidade. É sabido que, no processo de narrar, instauram-se, no fio do discurso, ditos e também silenciamentos, ou seja, é possível ouvir, a partir daquilo que é dito (intradiscurso), o que não foi dito, mas funciona produzindo sentidos.

\section{Estabelecidos, outsiders e a questão do sujeito}

Apropriamo-nos dos termos "estabelecidos" e "outsiders", de Elias e Scotson (2000), deslocando-os para uma perspectiva discursiva da linguagem. Tal deslocamento dar-se-á pela consideração e mobilização da noção de sujeito tal como é pensada pela Análise de Discurso de cunho materialista.

${ }_{8}$ Os termos designativos em questão, utilizados por nós ora no singular, ora no plural, serão explicitados mais adiante. 
O conceito de discurso da Análise de Discurso nos permite compreender a noção de sujeito. Enquanto prática simbólica que se inscreve na história, o discurso é concebido como efeito de sentidos entre locutores (PÊCHEUX, 1969). Como assevera Orlandi (1999, p. 21), "No funcionamento da linguagem, que põe em relação sujeitos e sentidos afetados pela língua e pela história, temos um complexo processo de constituição desses sujeitos e produção de sentidos e não meramente transmissão de informação".

Estamos aí diante de uma concepção de sujeito como posição-sujeito e não como um lugar sociologicamente passível de ser descrito. Discursivamente, o que funciona no discurso são as imagens que resultam de projeções imaginárias que permitem transpor as situações empíricas - os lugares dos sujeitos - para as posições dos sujeitos no discurso. É justamente nesse ponto - lugar e posição - em que está a diferença elementar entre a noção de sujeito de Elias e Scotson (2000) - aqui deslocada - e aquela adotada por nós. Se de um lado, há empiricamente uma divisão entre estabelecido e outsider - pensadas enquanto categorias empíricas e imaginárias (cf. ELIAS e SCOTSON, 2000) -, há, de outro, do ponto de vista material, posições, uma vez que sujeitos e sentidos se movimentam na história. Assim, nesse nosso trabalho, estabelecidos e outsiders não são pensados como locutores empíricos, mas enquanto posições que ocupam no discurso. A respeito da ideia de posição é preciso dizer duas coisas: $a$ ) as posições de sujeito não são conscientes, isto é, elas não são acessíveis a ele "ele não te acesso direto à exterioridade (interdiscurso) que o constitui" (ORLANDI, 1999, p. 49) e $b$ ) tais posições são produzidas na relação entre a língua e história, ambas capazes de falha, de deslize.

Psicanaliticamente, o sujeito estabelecido pertence à instância do eu narcísico, que não quer outra coisa senão vislumbrar a sua imagem na figura do outro. Assim, o estabelecido, embebido pelo amor que sente por si mesmo tal como no mito de Narciso, não consegue ver o outro que está a sua frente com tudo que isso implica (com seus conflitos, diferenças e contradições); o que ele vê é resultado de uma idealização, uma projeção imaginária de si no outro. Levando em consideração as condições de produção de nosso corpus, o narcisismo pode ser pensado como uma defesa ao caos que a presença da alteridade (do outsider) pode causar. Neste sentido, a atitude narcísica parece ser necessária para garantir o sujeito como tal, isto é, com sua ilusão de inteireza.

A respeito do outsider, discursivamente ele é pensado como o outro, o estranho que, por ser diferente, pode provocar diversos afetos como medo e atração. No caso do medo, podemos conjecturar algumas motivações que se dão no nível do inconsciente: o medo da despersonalização de uma suposta identidade homogênea, medo do 
desconhecido, medo de possíveis mudanças que podem(riam) resultar em deslocamentos importantes nos processos de identificação do sujeito.

Vale dizer que, dependendo das circunstâncias em que é produzido, o medo pode impedir uma relação mais profícua com o outro, impondo um muro entre os sujeitos. Assim, o que poderia instaurar uma relação significativa atravessada de possíveis deslocamentos, é produzido, no lugar, uma espécie de repulsa na relação eu-outro, favorecendo afetos hostis, por exemplo. Como afirma Coracini (2003, p. 149), "tanto no caso do medo como no caso da atração, é o mesmo desejo do outro, desejo da plenitude que move o amor ou o ódio", ou a resistência a uma determinada cultura e/ou grupo social, como comparece em nosso corpus.

Os casos em que o contato com o outro suscita uma forte atração podem ser explicados pelo viés psicanalítico como o desejo do outro, "desse outro que nos constitui e cujo acesso nos é interditado, esse outro que viria completar o um" (CORACINI, 2003, p. 149).

Vale aqui um esclarecimento sobre a noção de desejo. Segundo a Psicanálise, o desejo jamais é realizado, alcançado. Aliás, o desejo é sempre insatisfeito, por isso que ele nos move, nos impulsiona às coisas a saber, tais como: anseios pessoais e profissionais, só para citar dois exemplos. O desejo se desloca de um objeto a outro, em uma série infinita, portanto a falta é o que o estrutura: só desejamos o que não temos e, quando conseguimos, já não é mais desejo, desloca-se, pois, para outro lugar. Nas palavras de Coracini (2007, p.135), “É o desejo, nunca satisfeito, que nos move, que nos impulsiona a buscar, ao longo da vida, uma realização pessoal, profissional, ainda que, de tempos em tempos, nos demos conta de sua transitoriedade, de sua fragilidade, de sua incompletude."

Essa reflexão nos permite problematizar a questão da identidade. Diferentemente do que se poderia pensar, a identidade, longe de ser uma unidade estável e idêntica a si mesma, é compreendida, discursivamente, como instância em que se dão identificações ideológicas e inconscientes consequentes (ORLANDI, 1999, 2001).

Vários autores, de diferentes campos epistemológicos, têm inclinado o olhar para questões referentes à identidade, já que tem sido uma noção muito presente na modernidade e, fundamentalmente, na contemporaneidade. Kristeva (1994) mostra-nos quão complexa é a identidade. Para a autora, o estrangeiro habita em nós, já que somos o que o outro diz de/pensa sobre nós. Isso significa que a imagem que o sujeito tem de si não é obra do além, do acaso ou algo inato, orgânico. A imagem que o sujeito faz de si 
resulta do olhar do outro ou, noutros termos, vemo-nos a partir do olhar do outro, o que pode ser exemplificado pela célebre frase de Arthur Rimbaud, “Je est un outre”. É ele, o outro, que nós dá os contornos de nossos sentidos ou, pelo menos, a sua ilusão. Ao longo de toda a existência, vão se (re)construindo imagens a partir das relações que os sujeitos estabelecem consigo mesmos e com o outro sempre pela via do simbólico na história.

\section{Da análise do corpus}

Reiterando, o corpus de pesquisa é constituído de relatos de vinte e quatro moradores de CMA, os quais foram solicitados a falar sobre Campinas do Monte Alegre e a presença da UFSCar Lagoa do Sino na cidade. Trata-se de relatos que apontam para uma série de conflitos e embates que se mostram regulares no plano da formulação, os quais podem ser sintetizados nos seguintes termos: festas promovidas por estudantes e seu modo de comportamento (vestimenta e linguagem utilizadas); aumento do preço dos produtos em virtude do grande fluxo de novos moradores na cidade a partir da implantação do campus; exclusão dos estabelecidos a certos eventos festivos promovidos pelos universitários e, por fim, problemas referentes à infraestrutura da cidade. Há outros aspectos, mas estes, como dissemos, são regulares na fala dos entrevistados.

Do corpus é possível identificar a distinção de dois grupos de sujeitos. O primeiro deles diz respeito aos alunos que, aprovados no vestibular, desloca-se de outro lugar (cidades e estados brasileiros) para estudar na UFSCar Lagoa do Sino e morar em CMA. Vale dizer que são sujeitos que deixaram seus lares (chez soi) para morarem, por um tempo determinado (alunos e incluímos também servidores públicos), em uma cidade do interior paulista. Já o segundo grupo constitui-se de moradores estabelecidos que, em sua grande maioria, moram na cidade há mais de 20 anos.

Para o objetivo desse trabalho, traremos quatro relatos, dois referentes ao grupo dos estabelecidos (E) e dois, dos outsiders. Observe-se que utilizamos as iniciais E (estabelecido) e O (outsider), seguidas de números crescentes. Por fim, discutiremos os resultados apresentados na análise9.

\footnotetext{
9 Vale dizer tais relatos são significativos do ponto de vista do discurso, pois trazem regularidades importantes para a compreensão do funcionamento das relações discursivas e sociais estabelecidas entre ambos os grupos em análise. Portanto, a escolha pelos quatro relatos justifica-se por serem exemplificadores das regularidades aludidas acima (referimo-nos aos conflitos e embates acima citados).
} 


\section{Dos estabelecidos}

Antes de apresentarmos os relatos, é importante sinalizar ao leitor que nossa escuta deflagrou o desdobramento de uma subdivisão significativa a respeito dos estabelecidos (E). O quadro abaixo nos permite visualizar o funcionamento de uma relação paradigmática que estabelece sentidos e imagens para e sobre o outro (outsiders), mas também sobre si, observemos:

\begin{tabular}{|l|c|c|c|}
\hline GRUPO I & \multicolumn{2}{|c|}{ SUBDIVISÃO } \\
ESTABELECIDOS & A & $B$ \\
$\begin{array}{c}\text { Moradores antigos consideram a } \\
\text { implantação do campus da UFSCar } \\
\text { para CMA }\end{array}$ & um malefício & um benefício & $?$ \\
\hline
\end{tabular}

Uma subdivisão notável é observada no quadro acima: de um lado, moradores que se mostram intolerantes aos outsiders, significando a sua presença e, por extensão, a da UFSCar maléfica, nociva para a cidade e, de outro, moradores para os quais a criação do campus é benéfica, positiva, oportuna. A princípio, parece desenhar-se aí uma espécie de lógica binária fundamentada em uma restrita oposição. Como toda estrutura binária, esse tipo de oposição, característica da tradição metafísica favorece exclusões (DERRIDA, 2002).

Dos dois relatos dos estabelecidos (E) que escolhemos para este trabalho é possível depreender contradições significativas, apontando para sentidos importantes a serem compreendidos e analisados. Vale dizer, sentidos que contradizem e abalam (deslocam) essa dicotomia inicialmente observada por nós e sintetizada no quadro acima. Dito de outro modo, observamos que alguns sentidos escapam da dicotomia estabelecidos-outsiders, apontando para possíveis brechas e deslocamentos nas relações discursivas e sociais entre os sujeitos. Vejamos os dois recortes que seguem:

E1: Agora eu falo, que não foi só os estudantes que estragou a Campina, porque a calamidade daqui é difícil, sabe? Ela era desse tamainho (fez gesto com as mãos), por causa da universidade (UFSCAR) a Campina cresceu [...] O povo cresceu o olho nos estudantes para tirar proveito, porque "eles podem, eles são rico". Tudo aproveitou...construíram. Tá certo, só que tem o limite. Eles não pensam que eles precisam comer, eles têm que se vestir, eles gastam livro. Eu tenho dó, menina". [...] Eu acolhi elas como se fosse da família, foi assim que acolhi. Está com 3 anos que elas moram aqui. [...] Vou ficar com saudades das meninas da UFSCar. [...] Por mim os pais dela ficavam morando pra cá também. Quando eles foram embora, eu fique olhando, minhas lágrimas caia, é como se fosse da família. Eu não queria ser assim apegada com as pessoas". (grifos nossos) 
E2: [...] Uma outra coisa que trouxe de ponto negativo, quando montou a Universidade aqui na Campina, veio o jovem e o povo de Campina que era uma cidade pacata, não tava acostumado com bagunça. $O$ primeiro ano foi uma desordem na Campina, que dava delegacia todos os dias. Eu era funcionário público, então tinha os donos de casa, os proprietários, ia na delegacia porque não conseguia dormir, os jovens não deixam ninguém dormir, virou muita bagunça, em vez de estudar queria só bagunçar. [...] A universidade trouxe problema? Trouxe, como qualquer outro lugar traz. Traz prostituição, traz drogas, isso é normal. E a Campina não está preparada. Infelizmente nós não temos uma saúde adequada para atender essa demanda que nós temos hoje [...] Eu acho muito bacana a relação entre os alunos e os moradores, inclusive os alunos tem o maior respeito com a gente, com todo mundo, chama a gente de tio. Os professores então nem se fala. Eu vejo essa relação de todos os moradores daqui com os universitários, melhor é impossível. Virou famílias. Eu vejo que fazem churrasco, faz almoço na casa, convidam o professor, o aluno...virou família, fico muito bacana isso daí, é muito ótima a convivência entre o pessoal da universidade com os moradores de Campina. [...] O poder público precisava investir numa mudança, numa limpeza da cidade, investimento em lazer, mas infelizmente tá deixando a desejar. O universitário traz desenvolvimento. Eles querem festa. Se você fizer uma festa, tem gente suficiente pra gastar, pra se divertir. Entendeu? A praça nossa era muito mais bonita, hoje a praça tá acabada, tá tudo escuro. Tem que ter atração para segurar esse jovem, se não o jovem sai para outras cidades e deixa o município. É isso que tá faltando. Eu vejo opção para segurar o jovem e eles se divertir para fazer a festa deles.... E a festa deles, eles gastam, consomem, eles compram bebida no mercado, compram pão na padaria para vender lanche. Eles fazem uma festa que vira um comércio através da festa deles. Alguém ganha e são os alunos [...] o lazer deles é a festa que eles fazem. (grifos nossos)

Em ambos os relatos há um funcionamento discursivo que é sintoma do modo como os enunciadores representam a presença do outsider na cidade: a irrupção de um desejo de política a partir do reconhecimento pela solução de conflitos, como, por exemplo, no caso apontado pela E1, a mitigação da exploração econômica contra os universitários. Trata-se de um reconhecimento de que não se deve explorar economicamente os novos moradores, neste caso os alunos em sua maioria: (E1) "Eles não pensam que eles precisam comer, eles têm que se vestir? Eles gastam livro. Eu tenho dó, menina" (grifos nossos).

Note-se que o primeiro "eles" não coincide com o segundo. Enquanto o primeiro refere-se a uma parte dos estabelecidos, mais exatamente àqueles que detêm o poder (são eles proprietários de casas e kitnets e estabelecimentos comerciais, como mercados, lojas em geral etc.), o segundo alude-se aos outsiders, especialmente aos alunos que saíram de suas cidades/Estados para morar (ser hóspedes de) em CMA provisoriamente. 
Abre-se aqui um parêntese. É importante esclarecer que, a respeito dos estabelecidos, nem todos são proprietários de casas, kitnets ou de comércio. Uma parte importante dos cidadãos de CMA é camponesa que, como tal, (sobre)vive do cultivo da terra. Com a chegada da UFSCar, a lógica capitalista tornou-se determinante das relações entre os sujeitos em CMA e região.

O desejo de política surge da necessidade de se criar uma harmonia (ainda que imaginária) para que haja convivência entre estabelecidos e outsiders. A polis comparece como o lugar no qual se faz política porque é nela que irrompem as diferenças, os (des)encontros, os embates, enfim conflitos postos pela diferença. Vale dizer que, em nossa civilização, a política, enquanto Estado, é a instância responsável pela resolução dos embates, pela tentativa de amenizar os conflitos resultantes do confronto com a alteridade. Vale lembrar aqui do pensamento aristotélico de que o homem é um animal político, sendo a política o espaço a partir do qual os homens discutem, planejam e executam medidas para viver coletivamente.

No Dicionário de política Bobbio (1998) assinala que a palavra política, intrinsecamente relacionada à cidade, ao público, ao urbano, diz respeito às várias formas de governo, com a significação mais comum de reflexão sobre as coisas da cidade.

Na perspectiva clássica, que é idealista, a ideia de política é aquela vinculada ao sentido de bem comum (busca do bem-estar comum). Já para uma perspectiva materialista, a qual nos filiamos, a política pode ser pensada como uma das formas pelas quais se manifesta a luta de classes.

Rolnik (1988) assevera que, desde sua origem, a cidade significa, ao mesmo tempo, uma maneira de organizar o território e uma relação política. Assim sendo, habitála significa participar, ainda que timidamente, da vida pública, mesmo que seja submetendo-se aos seus regulamentos e, acrescentaríamos, reivindicando, ao mesmo tempo, por melhores condições materiais de existência, tal como se revela em nosso corpus.

O que o relato da enunciadora (E1) deixa entrever é, como dissemos, a exploração econômica da parte do empresariado, de um lado, e a indignação por tal exploração, de outro, resultando, este último, no desejo de política por parte dos estabelecidos, mais exatamente aqueles que se projetam, no plano do imaginário, no lugar dos outsiders. Esse desejo de política ao qual nos referimos faz parte de um discurso mais amplo: o discurso da consciência social pelo qual parte dos moradores estabelecidos é interpelada. 
Neste caso, o sentido de política que comparece como memória discursiva é aquele que se relaciona à busca de ações para o bem-estar coletivo, mais exatamente o bem-estar dos outsiders, que são, em sua maioria, universitários com limitadas condições econômicas, alguns deles dependem de auxílio moradia e alimentação para a permanência tanto na universidade quanto na cidade. Faz-se pertinente um questionamento: o que significa bem-estar para a enunciadora em questão (trabalhadora, assalariada, mãe e avó) parece não significar o mesmo para os proprietários (comerciantes) de CMA...

A respeito da preocupação da $\mathrm{E} 1$ com os universitários, podemos dizer que estamos longe daquilo que Jean-François Mattéi (2002) chama barbárie intima, que consiste no enfraquecimento da capacidade de pensar resultante do enclausuramento dos sujeitos em si mesmos, nas suas vidas e em seus grupos identitários. O filósofo pósmoderno concebe a barbárie como o movimento que vai na direção oposta ao movimento da civilização: em direção à intimidade, ao interior de si; um movimento para dentro do sujeito. Diferentemente, os sujeitos de nossa pesquisa, antigos moradores de CMA, não se refugiam na intimidade, mas, criam laços sociais, afetos que enlaçam os sujeitos colocando-os em um processo de convivência ética, o que torna o espaço público um lugar possível de engajamento graças ao estabelecimento das relações postas. Como é possível observar, na fala do E2 fica explícito o desejo pela resolução dos problemas referentes à cidade, problemas esses que podem afastar, segundo ele, o estudante da cidade de CMA: “[...] a praça nossa era muito mais bonita, hoje a praça tá acabada, tá tudo escuro. Tem que ter atração para segurar esse jovem, se não o jovem sai para outras cidades e deixa o município. É isso que tá faltando. Eu vejo opção para segurar o jovem e eles se divertir para fazer a festa deles....".

Embora o enunciador (E2) traga a ideia de que os alunos aquecem a economia da cidade, garantindo lucro ao empresariado, sinaliza-se, contraditoriamente, uma preocupação com os jovens em mantê-los na cidade de uma forma saudável, prazerosa e segura:

"[...] Se você fizer uma festa, tem gente suficiente pra gastar, pra se divertir. Entendeu? E a festa deles, eles gastam, consomem, eles compram bebida no mercado, compram pão na padaria [...] O poder público precisa investir numa mudança, numa limpeza da cidade, investimento em lazer [...] tem que ter atração para segurar esse jovem [...] A praça nossa era muito mais bonita, hoje a praça tá acabada, tá tudo escuro [...]”. (grifos nossos) 
Pelo menos no que diz respeito aos três aspectos observados acima (segurança, bem-estar e saúde, cf. os termos em negrito), não há esvaziamento do espaço público, como em Sennett (1999). Embora haja conflitos em virtude da presença de diferentes sujeitos no espaço da cidade, tal como veremos mais adiante (conforme análise referente a uma parte do grupo II), estamos frente a uma cidade cujos espaços são preenchidos de sentidos, relações, afetos, como parte do corpus permite ver.

Desse modo, a possibilidade do afeto não está adormecida, ao contrário. Neste caso, a polis comparece como: “[...] o fórum no qual se torna significativo unir-se a outras pessoas". Daí a motivação para o surgimento da cidade: "a cidade surgiu como foco para vida social ativa [...], para a experiência das possibilidades humanas, durante a maior parte da história do homem civilizado" (SENNETT, 1999, p. 414). No entanto, na sequência dessa citação, Sennett (1999, p. 414), de modo pessimista, continua, “[...] mas hoje em dia essa possibilidade civilizada está adormecida". Como dissemos, em nosso caso, se, de um lado, há conflitos postos pela diferença - diferença trazida pelo hóspede (alunos em sua maioria) -, de outro, há uma injunção por sua resolução, pela síntese.

O estranho é acolhido pelos estabelecidos, tornando-se "quase” da família; família que agora é habitada pelo estranho - o de fora -, que é hóspede. Como tal, o hóspede, que mora provisoriamente no lar que o hospeda, é tratado "como se fosse da família", ou seja, o hóspede continua sendo hóspede, não é da família, mas como fosse! Argumenta a favor ao trazer na formulação a palavra "família", no entanto faz presente uma distância importante entre quem é e não é membro dela, o que acentua a diferença entre quem é o hospedeiro (morador estabelecido) e quem é o hóspede (morador outsider).

Retornemos ao relato da E1, mais exatamente o recorte a seguir:

“[...] Eu acolhi elas como se fosse da família, foi assim que acolhi... está com três anos que elas moram aqui... Quando eles [os pais das alunas] foram embora, eu fique olhando, minhas lágrimas caíam, é como se fosse da família". Relato da moradora antiga que aluga sua casa do fundo para duas alunas da UFSCar."

Neste relato, observamos o funcionamento daquilo que Derrida (1996) nomeia de entre, noção essa profícua nesse ponto da análise. A formulação "como se fosse da família" traz em seu bojo o estar-se na fronteira, o que estabelece uma relação de aproximação incompleta que não cruza totalmente a fronteira, nem dela permanecem aquém, mantendo o outro como outro, resistindo ao desejo de assimilá-lo, de desvendar sua verdade (como se fosse possível!): "relação maluca, uma relação sem relação, que 
entende o outro como outro numa certa relação de incompreensão" (DERRIDA, 1996, p. 82).

Esse modo de representação das relações entre moradores antigos e novos pela via do reconhecimento do outro como ente da família pode ser vislumbrado na fala do E2: "Eu acho muito bacana a relação entre os alunos e os moradores, inclusive os alunos tem o maior respeito com a gente, com todo mundo, chama a gente de tio. [...] Virou famílias. Eu vejo que fazem churrasco, faz almoço na casa, convidam o professor, o aluno...virou família". Este último sintagma "virou família" traz, no nível da formulação, o reconhecimento do outro (outsider) - como um membro da família.

No entanto, considerando o corpus em sua totalidade, vemos que há uma oscilação, hesitação, em reconhecer o outro (outsider) como membro da família.

Contraditoriamente, na fala dos dois enunciadores (E1 e E2), apesar de considerarem imaginariamente o outro (o hóspede) como um (quase) ente da família, esse mesmo outro comparece como um estranho. A existência dos novos moradores é representada como algo subversivo, perturbador, estranho, desviante. Contradição interessante para Psicanálise: no corpus, aquele que traz a prostituição e as festas é justamente aquele considerado como um "quase" da família. O anfitrião abre as portas da casa para o diferente dele, o estranho. Conforme o E2, um dos problemas que a universidade trouxe foi a prostituição, mas, lembremos, ao longo do relato o mesmo enunciador afirma, referindo-se aos alunos: "Virou família": "[...] A universidade trouxe problema? Trouxe, como qualquer outro lugar traz. Traz prostituição, traz drogas.”.

Ou seja, o estranho agora faz (é) parte da família. Estranho e familiar habitam o mesmo espaço da polis, da casa, da família, que, por sua vez, é o mesmo que produz bagunça, sentido que irrompe na seguinte formulação: “[...] ia na delegacia porque não conseguia dormir, os jovens não deixam ninguém dormir, virou muita bagunça, em vez de estudar queria só bagunçar”.

Vale aqui uma pausa para pensarmos a questão do estranho-familiar via Freud (1996 [1919]). A tradução do termo linguístico "unheimlich" para algumas línguas aponta para acepções como: estrangeiro, lugar estranho, inquietante, desconfortável, sombrio, escuro, assombrado, repulsivo, sinistro, suspeito, demoníaco e por aí vai. O texto de Freud trabalha com uma ambiguidade fundamental: heimlich, que indica aquilo que é da ordem do familiar, também significa algo secreto e oculto, o que, contraditoriamente, aproxima essa palavra de seu oposto, unheimlich. Voltaremos a essa questão. 
Voltando ao corpus, há um deslize de sentido que se dá no nível dos tempos verbais, entre o pretérito e o presente. O E2 inicia sua fala com verbos conjugados no passado: "montou", "veio", "tava", "foi" e desliza para o tempo presente > "deixam": "[...] os jovens não deixam ninguém dormir, virou muita bagunça"; na sequência, volta a conjugar o verbo no passado "em vez de estudar queria só bagunçar". Tal oscilação denuncia o modo de representação do outsider pelo estabelecido. $\mathrm{O}$ fato de os jovens não deixarem ninguém dormir parece perdurar, produzindo o sentido de que eles ainda só querem bagunçar, ao invés de estudar: “[...] ia na delegacia porque não conseguia dormir, os jovens não deixam ninguém dormir, virou muita bagunça, em vez de estudar queria só bagunçar".

Há um duplo movimento tecendo o fio do discurso: repulsa e atração, ou seja, ao mesmo tempo em que repele, aproxima. Movimento tenso entre o antigo morador e o hóspede, isto é, aquele que vem de fora (o estranho), mas que é levado para dentro (o familiar), compartilhando estranho e familiar o mesmo espaço: o da cidade que migra, parafrasticamente, para casa que, contraditoriamente, abriga um elemento dionisíaco: a prostituição, além da libertinagem e drogas (cf. E2). Tais elementos são regulares não somente no E2, mas principalmente na maioria das entrevistas que constituem o corpus na íntegra. Noutros termos, hospeda-se em casa - no chez moi - aquele/aquilo que é da ordem do estranho-familiar: o estrangeiro traz em sua bagagem o estranho, o obscuro, o inusitado, produzindo, no campo do outro, um misto de atração e desconforto. Diríamos que ambos, hóspede (outsider) e hospedeiro (estabelecido), sem o saber, fazem com o que "aquilo que deveria ter permanecido "secreto e oculto" venha à tona". (MARTINI e COELHO JR., 2010, p. 373-4).

Ainda com relação ao E2, é interessante o movimento de sentidos produzido entre os termos prostituição e doença: "A universidade trouxe problema? Trouxe, como qualquer outro lugar traz. Traz prostituição, traz drogas, isso é normal. E a Campina não está preparada. Infelizmente nós não temos uma saúde adequada para atender essa demanda que nós temos hoje." Aqui há um deslocamento de sentidos importante: "Universidade $>$ cidade $>$ prostituição $>$ doença". Tudo se passa como se a Universidade trouxesse a prostituição que, por sua vez, é significada como doença, ou seja, o aluno universitário é um tipo de doença que, ao chegar à polis, a infesta. O que significa que, ao abrir as portas de sua casa, o hospedeiro abre para o hóspede que a infesta com a doença que traz na bagagem: prostituição e drogas. Esse sentido negativo da existência da Universidade na cidade pode ser vislumbrado na fala da E1, que relata: "Agora eu falo, 
que não foi só os estudantes que estragou a Campina, porque a calamidade daqui é difícil, sabe? Ela era desse tamainho (fez gesto com as mãos), por causa da Universidade a Campina cresceu". Deixa-se entrever que os estudantes estragaram Campina - ao menos uma parte dela -, estrago que se faz ao modo de uma calamidade. Do campo semântico da palavra calamidade podemos depreender algumas expressões parafrásticas, tais como: destruição, grande infortúnio, catástrofe, desgraça pública. O estrago ao qual a E1 se refere tem o tamanho de uma calamidade. Conforme o relato, a cidade passou e passa por uma calamidade, sentido esse justaposto à ideia anterior “[...] não foi só os estudantes que estragou a Campina". Pela direção argumentativa posta, entende-se que quem causou ou tem provocado uma catástrofe (calamidade) na cidade foi/é os alunos principalmente, que migra, parafrasticamente, para "os alunos são a própria calamidade".

Abramos aqui um parêntese. Trazendo para a consideração a reflexão que Derrida tece em seu livro "De l'hospitalité", mais exatamente a leitura que faz da obra de Benveniste Le vocabulaire des instituitions indo-européennes, o termo latino hostis (presente no termo hosti-pet-s, que designa o poder de acolher, de dar hospitalidade) traz uma indistinção consequente: hostis é ao mesmo tempo aquele que acolhe, aquele que é acolhido e ainda o inimigo. Benveniste propõe o seguinte esquema linguístico: "estrangeiro favorável > hóspede", "estrangeiro hostil > inimigo".

Deslocando tal reflexão para o nosso corpus, o hóspede, tal como comparece no imaginário dos estabelecidos (anfitrião), é um inimigo em potencial porque pode trazer consigo peste, doença, infecção, vírus. Isso tem que ver com o fato, segundo Derrida, de que a questão da hospitalidade não é da ordem da intencionalidade, o que significa que o hóspede não é propriamente um convidado, mas um visitante. Para o autor, o convite e a visitação se configuram como a diferença entre o estrangeiro e o outro absoluto (ou o recém-chegado [nouvel arrivant]). O outro absoluto é o impossível, o fora-da-regra, forada-lei. Ele é o que acontece, o que chega (ce qui arrive) sem aviso, sem pedir licença.

\section{Dos Outsiders}

O outsider é aquele que sai de sua cidade - estado, para alguns -, para morar em uma cidade diferente da sua e desconhecida para a maioria; pequena (do interior de São Paulo), com hábitos, costumes e valores totalmente distintos dos seus; longe da casa - e, mais do que isso, do suposto aconchego do lar-, dos familiares, em uma palavra: da mãe. De uma perspectiva psicanalítica, pode-se dizer que tal mudança desvela uma situação de desamparo na qual a falta de sua casa/lar/cidade mergulha o outsider. 
Para preencher, provisória e imaginariamente, o vazio que a situação de desemparo traz, o outsider inscreve-se na cidade, ou seja, (re)inventa uma cidade em que possa se dizer - mais dizer do que ser dito - na tentativa de encontrar nela sentido(s). Vale dizer, cidade que é extensão de sua casa (lar), que é e não é sua ao mesmo tempo. Perguntamo-nos: não seria esse o entre-lugar(es) derridiano?

Parafraseando Coracini (2007, p. 132) quando discorre sobre o entre-(outro[a]s)línguas a partir da noção de différence de Derrida (1972 [1975]), poder-se-ia dizer que a cidade constitui-se como um entre-lugar(es): espaço impossível de se marcar a divisa e de delinear sua origem, no espaço confuso (difuso?) entre o dentro e o fora, o mesmo e o diferente.

Importa dizer que aquilo que comparece como objeto de queixa do estabelecido (ao menos uma parte deles) - festas, barulho, bar, música, dança, encontro com colegas à noite, bebida, vestimentas etc. - sinaliza a presença do outro, produzindo conflitos e embates na cidade. O outro se mostra, transborda no espaço material da cidade, o que produz, por sua vez, intolerância como um dos afetos produzidos10. Ao mesmo tempo, todos os elementos motivos de queixa dos estabelecidos comparecem como o lugar no qual grande parte dos outsiders encontra amparo. Reiterando: uma busca suscitada pelo vazio (desamparo) causado pela mudança brusca de um lugar conhecido (familiar) para um lugar que não é o seu (estranho). Essa forma de inscrição da subjetividade se faz pela resistência, modo pelo qual o outsider encontra brecha para a obtenção de prazer ou de suavizar o sofrimento por estar fora de sua casa, do conhecido, do familiar. Esse seria um modo de lidar com o mal-estar na civilização (FREUD, 1996 [1929]), civilização essa (“a dos estabelecidos”) que, embora tenha suas leis e modos de organização específicos, permite ao outsider se subjetivar pela via da resistência, já que seu corpo não encaixa no ideal procutiano11 que constitui o imaginário daqueles.

Ao mesmo tempo, é preciso considerar que, com base nos relatos dos outsiders, há também um desejo de estabelecimento de normas, regras, o que nos permite dizer que regras não vêm somente da parte daquele que hospeda. Como veremos no recorte a seguir, determinar preços diferentes para a entrada em festas - festas organizadas pelos alunos

10 Referimo-nos aqui a uma parte dos estabelecidos apenas.

11 A título de esclarecimento, Procusto, considerado um bandido, vivia em Elêusis e tinha uma cama feita de ferro, com seu exato tamanho, para a qual convidava viajantes a se deitarem. Caso os hóspedes fossem altos demais, ele amputava o excesso de comprimento para ajustá-los à cama, já aqueles que tinham estatura pequena eram esticados até atingirem o comprimento suficiente. De nossa parte, o personagem da mitologia grega simboliza bem o ideal (efeito) de homogeneidade e unicidade que atravessa o imaginário social. 
da UFSCar -, ou ainda, estabelecer o público que poderá frequentá-las é também um modo de marcar território - o seu território, ainda que provisório. Observemos:

O1: Quando a gente faz festa eles [estabelecidos] querem ir também, eles querem participar das coisas que os alunos fazem. Já chegou a dar problemas de o pessoal pular muro pra entrar em festa. Assim, eles querem participar e quando a gente faz algum role fechado, alguma coisa assim, eles ficam chateados "Poxa, não abriu pra cidade". As festas geralmente são abertas, mas paga ingresso e aí os universitários pagam um preço e aí o pessoal da cidade paga um pouco mais caro. Tem umas que não têm isso, é o mesmo preço para todo mundo. Geralmente as festas são abertas, são poucas as festas fechadas. Mas as fechadas que eu ouvi falar sempre trazem problema de o pessoal querer entrar e não poder. Ai o pessoal fica chateado, reclama depois. É uma relação de amor e ódio que taí aí que eu consigo ver. (grifos nossos)

Trata-se de um relato que traz para a consideração o modo como as festas funcionam, mais precisamente as festas organizadas pelos próprios alunos da UFSCar. Nas festas fechadas somente o público que frequenta o campus é autorizado a entrar (alunos e servidores), o que nos permite afirmar que há aí uma interdição explícita do outro: impede-se a presença e circulação do corpo dos moradores estabelecidos no espaço em que as festas acontecem. A resposta a essa hostilidade surge do gesto de pular o muro para adentrar um espaço que lhe foi proibido: “Já chegou a dar problemas de o pessoal pular muro pra entrar em festa. Eles querem participar e, quando a gente faz algum role fechado, alguma coisa assim, eles ficam chateados: “_Poxa, não abriu pra cidade?"”.

O gesto de pular o murro é, a nosso ver, um ato no nível do simbólico (PÊCHEUX, 1969): um trabalho histórico do corpo do sujeito sobre o discurso da interdição instalado. Tal gesto indica que o morador estabelecido tem o desejo de socializar com os outsiders e participar das mesmas ações em que estes atuam e as quais organizam. Em suma, o estabelecido não é indiferente ao outsider, mas o contrário não é verdadeiro, neste aspecto referente às comemorações festivas.

Já nas festas abertas, o público - moradores que não estão diretamente ligados à UFSCar - também pode entrar, na condição de pagar um pouco mais do que pagam os outsiders. Tanto a modalidade aberta (pública) quanto a fechada (privada), as festas funcionam como espaço-enquadramento (HENRY, 1998, apud ORLANDI, 2015), no sentido de que enquadram fenômenos e práticas que se dão na cidade. Neste caso, o espaço funciona como parte do acontecimento discursivo urbano. Nas palavras de Orlandi (2015, p. 12-13), "Portanto, não se trata nem do espaço empírico, nem do espaço concreto, 
material, em si, mas desse espaço material que significa, que tem a sua historicidade: espaço de significação, afetado pela interpretação, pela ideologia”.

O relato de $\mathrm{O} 1$ nos leva a compreender que há um modo de organização social implicado na relação eu-outro no contexto da cidade, cindindo rigidamente quem é quem: estabelecidos, de um lado, e outsiders, de outro. Desta vez, a exploração do capital vem dos outsiders ao cobrarem um valor maior dos moradores antigos da cidade, os estabelecidos. É produzida aí uma cisão estrita que traz consequências importantes para o espaço e para seus habitantes, todos eles: a hostilidade insurge como afeto que impede a possibilidade de vínculo social, restringindo as relações entre os diferentes sujeitos aí implicados. Como afirma Orlandi (2011), a ideia é que os sujeitos possam habitar a cidade sem restrições: lugar público, social, político. Só assim os sujeitos sentir-se-ão em casa, onde quer que estejam: “Com nossos concidadãos. Nossos iguais. Em uma sociedade que seria, aí sim, democrática" (ORLANDI, 2011, p. 702).

A partir das questões concernentes às festas, observamos que as diferenças sociais, culturais e econômicas se manifestam violentamente e a divisão social se sobrepõem à materialidade da divisão do espaço urbano, reduzindo, assim, o espaço da sociabilidade e convivialidade: “[...] eles querem participar e quando a gente faz algum role fechado, alguma coisa assim, eles ficam chateados "Poxa, não abriu pra cidade". As festas geralmente são abertas, mas paga ingresso e aí os universitários pagam um preço e aí o pessoal da cidade paga um pouco mais caro." (grifos nossos).

A nosso ver, o que poderia ser um momento produtivo na relação entre os sujeitos, torna-se, ao contrário, uma arena de hostilidade. Daí a nossa pergunta: Por que "o pessoal da cidade" paga mais que os "universitários"?

A fala da enunciadora $\mathrm{O} 1$ traz uma contradição: os universitários, embora habitem na cidade de Campina do Monte Alegre, não fazem parte do que denomina "pessoal da cidade". Há uma cisão que se materializa no plano da língua: "os universitários" não pertencem à cidade nem o "pessoal da cidade" pertence à Universidade: "[...] aí os universitários pagam um preço e aí o pessoal da cidade paga um pouco mais caro."

Ao impedir que o outro adentre o espaço da festa (as festas fechadas), é produzida uma violência social, que é separar sujeitos de sujeitos igualmente cidadãos, mas que passam a ser tratados como ameaça. Por este gesto fica dito que os que estão de fora da festa ou que pagam mais são os moradores com os quais (não) se quer conviver, ou seja, quem está para fora da festa são os que se exclui ou, na pior das hipóteses, aqueles cuja existência nos é indiferente. 
A análise tem mostrado que, se há, de um lado, momentos de hostilidade, inclusive de ambos os grupos, há, de outro, espaço para relações de afeto que enlaçam os sujeitos, estabelecendo vínculos importantes para uma convivência (relativamente) respeitosa e acolhedora. O relato que segue é de uma estudante da UFSCar, do curso de Biologia da Conversação, que narra a amizade que fez com uma catadora de lixo, antiga moradora, já idosa, de CMA. Reiterando o que já afirmamos no início desse trabalho, os relatos escolhidos são representativos de alguns funcionamentos que se mostram regulares na relação estabelecido-outsider. Assim como o relato abaixo $(\mathrm{O} 2), 12$ há outros com funcionamento similar que não aparecerão no corpo do presente trabalho, mas estão sendo considerados na análise global proposta.

O2 [Parte 1]: Acho que quando você se instala, passam seis meses, querendo ou não, você vai ver a pessoa todos os dias, vai ver a pessoa da farmácia, do barzinho, do mercado, a pessoa que cata reciclagem na sua casa. Por que não dizer um oi, tudo bem, posso ajudar? Foi o que aconteceu aqui em casa, fiz amizade com a senhorinha da reciclagem, foi mais ou menos isso. Eu tinha acabado de colocar o lixo pra fora da minha casa. Na época eu não separava. E ela foi revirar o meu lixo. Assim que ela foi, eu disse: “_Oi tudo bem? Posso ajudar a senhora?”. Ela ficou super sem graça e ela botou a mão pra traz e disse: “_Nossa moça, desculpa, eu não sabia”. [A aluna disse:] "Não, não, pode ficar tranquila, é que o lixo não está separado, mas passa final de semana que eu vou separar tudo o lixo para senhora, que é mais fácil, poupa serviço para senhora!”. Ela ficou super animada, muito agradecida, e foi embora. Aí passou outro final de semana, eu fiquei esperando ela, porque eu consegui ouvir o barulho do carrinho dela. Aí eu já dei um grito, "Espera aí que eu estou descendo". Desci e entreguei a reciclagem, ela perguntou se podia me dar um abraço. Aí eu abracei ela, aí toda vez que ela me vê, ela dá um grito: “_Oi, menina!". Ela me abraça e me dá um beijo. Independente de sol e chuva, a gente pára para conversar Eu conheci a netinha dela, sobrinha dela, a cunhada dela, conheci todo mundo, toda a família dela. No aniversário dela, eu guardei a data de aniversário dela, aí eu dei um bolo de presente. Eu sou assim, já chamo pra tomar café. (grifos nossos).

A enunciadora mostra-se aberta ao outro no sentido de criar um laço, uma relação de sociabilidade entre novos e antigos moradores. Ao modo de uma pergunta retórica, enuncia: “_Por que não dizer um oi, tudo bem, posso ajudar?”. Cumprimentar, ser solícito, preocupar-se com outro são, todas elas, formas (tentativas?) de aproximação, de se inscrever na cidade a fim de nela fazer morada (seu lar). E fazer morada aqui significa estabelecer vínculo social.

12 Dividimos o relato em duas partes para que possamos fazer os apontamentos que julgamos importantes de modo que fique mais explícita para o leitor e o analista a compreensão das relações estabelecidas entre eu-outro. 
Soma-se a esse gesto o cuidado da $\mathrm{O} 2$ (outsider) com a senhora da reciclagem ao separar o lixo a fim de poupar o seu tempo e trabalho: “[...] o lixo não está separado, mas passa final de semana que eu vou separar tudo o lixo para senhora, que é mais fácil, poupa serviço para senhora!". Tal cuidado fez resultar um laço importante entre elas, uma espécie de amizade que tem perdurado: “[...] Desci e entreguei a reciclagem, ela perguntou se podia me dar um abraço. Aí eu abracei ela. Aí toda vez que ela me vê, ela dá um grito: “_Oi, menina!”. Ela me abraça e me dá um beijo. Independente de sol e chuva, a gente pára para conversar."

Outro evento que consideramos importante nessa relação de cumplicidade que aí se instalou é a lembrança da data de aniversário, bem como o bolo e o "presentinho" preparados pela moradora (cf. parte 2, abaixo): "No aniversário dela, eu guardei a data de aniversário dela, aí eu dei um bolo de presente [...] Fiz um crochê, um cachecol de crochê e uma touquinha. Aí eu falei: “_Esse é um presentinho já adiantado de aniversário”.

Segue a segunda parte da entrevista:

O2 [Parte 2]: Eu morei um tempo sozinha. Eu fiz amizade muito fácil com os moradores, no sentido assim de...eu chegava a conversar, e eles "vamos tomar um café na minha casa?", ou as senhorinhas na rua perguntavam: "_Onde você está indo?" [...] Hoje eu tenho amizade com a moça do açougue, a moça do caixa, do mercado, com a pessoa que pega reciclagem na minha casa. Eu acho muito bonitinho: quando eu saio, a senhorinha que cata reciclagem lá em casa, ela grita: "Oh menina!". Eu digo "Dona Maria, vem tomar café na minha casa!". Se a pessoa me vê arrumada, já fala “" Você está indo pra festa?”. Eu tenho amizade com quase todo mundo. Então quando eu vou nas festas, eu procuro estar com o meu grupo da UFSCar, mas se eu conheço alguém da Campina, porque não agregar o grupo da UFSCar, né? [...] Como estava muito frio, fiquei sabendo que ela ficou internada. Aí fiquei com muita dó. Fiz um crochê, um cachecol de crochê e uma touquinha. Ai eu falei: “Esse é um presentinho já adiantado de aniversário". Porque eu sei que está muito frio e ela sai cedo para pegar reciclagem. Aí no dia em que ela me viu, ela quase chorou. Eu fiquei preocupada por ela ter ficado internada duas vezes. Deve ser por causa de frio, porque ela sai muito cedo. Ela me abraçou, ela não sabia como me agradecer por causa de um bolo e um cachecol (grifos nossos).

Interessante observar que a $\mathrm{O} 2$ (cf. parte 2) projeta-se, imaginariamente, no lugar da senhora da reciclagem, conjecturando, preocupada, a possiblidade de a sua exposição ao frio (relento) ter sido causa da internação: "Porque eu sei que está muito frio e ela sai cedo para pegar reciclagem" [...] Eu fiquei preocupada por ela ter ficado internada duas vezes. Deve ser por causa de frio, porque ela sai muito cedo" (o grifo é nosso). A locução verbal hipotética “deve ser” materializa, no plano da língua, a imagem que a enunciadora 
faz a respeito da possível causa da doença que levou a senhora da reciclagem à internação e materializa-se o cuidado com a sua interlocutora.

Observamos um ponto de equívoco importante entre estabelecidos e outsiders na dicotomia entre aquele que é de fora e aquele que é de dentro. O relato da aluna expõe uma fissura que parece ser estruturante das relações socioeconômicas da/na cidade: alguns moradores, como é o caso da enunciadora que tira seu sustento do lixo reciclado, também são outsiders do ponto de vista da cidadania, de direitos e deveres, de pertencimento ao grupo economicamente ativo. Nesse e noutros relatos que constituem nosso corpus na íntegra, escancaram-se as condições humanas precárias do trabalho informal e o modo como a sociedade tem tratado seus idosos principalmente: "Porque eu sei que está muito frio e ela sai cedo para pegar reciclagem. Aí no dia em que ela me viu, ela quase chorou. Eu fiquei preocupada por ela ter ficado internada duas vezes. Deve ser por causa de frio, porque ela sai muito cedo.”.

Esse trecho da entrevista expõe as contradições próprias de uma sociedade capitalista pautada nos ideais neoliberais, que tem a desigualdade social e econômica como fator estruturante das relações entre os sujeitos na contemporaneidade, sem mencionar ainda a precarização do trabalho como a face mais cruel do neoliberalismo: "Deve ser por causa de frio, porque ela sai muito cedo". Em nosso caso, acrescente-se a desigualdade que se materializa no nível do letramento: observe-se que é a aluna universitária (outsider) que ajuda e socorre a moradora estabelecida, catadora de lixo reciclado. É de fora, mas é também de dentro uma vez que tem acesso ao conhecimento legitimado cultural e socialmente. A esse patrimônio a moradora estabelecida (catadora de lixo reciclado) não é detentora. Por isso, ousamos dizer que ela também é uma outsider, uma vez que está à margem (marginalizada) das riquezas produzidas no contexto em que está inserida, em uma palavra, em sua cidade.

Assim, a cidade se mostra através de suas contradições: nem todos os estabelecidos têm acesso aos bens materiais nela produzidos, permanecendo invisíveis no espaço urbano. Como bem afirma Haroche (2005), na atual sociedade, o signo da invisibilidade é sinônimo de inutilidade, de inexistência, de insignificância. A esse respeito, Orlandi (2016, p. 224) assevera com propriedade, "O segregado não faz parte da sociedade, por definição: está fora e, estando fora, é não existente. É o resto que se elimina". Nessa lógica da segregação, elimina-se o lixo, assim como são eliminados (descartados) certos sujeitos. 
Isso nos leva a repensar os sujeitos (estabelecidos e outsiders) na relação com a chamada urbanidade: excluída do grupo economicamente ativo da cidade, a moradora estabelecida, tal como os outsiders, é também aquela que não pertence, é o de fora, o estranho. Levando em consideração a dicotomia "estar fora" (outsiders) e "estar dentro" (estabelecidos), podemos dizer que alguns estabelecidos estão na cidade, mas não são parte do urbano, estão excluídos dele, são estranhos (estrangeiros) a ele.

Nesse sentido, estar na cidade, ser moradora antiga (estabelecida) não garante o acesso a determinados bens. Em uma palavra, estar na cidade não significa o mesmo que pertencer a ela com tudo o que isso implica. E isso se dá em razão da existência de uma política discriminatória que produz segregação entre estabelecidos e estabelecidos: sim, todos são estabelecidos, mas uns são menos que outros!

É importante levar em consideração que a solidariedade que atravessa a fala da moradora outsider e que se materializa no gesto cuidadoso e preocupado com a moradora estabelecida catadora de lixo é um dos componentes do capitalismo: "Como estava muito frio, fiquei sabendo que ela ficou internada. Aí fiquei com muita dó. Fiz um crochê, um cachecol de crochê e uma touquinha [...] Porque eu sei que está muito frio e ela sai cedo para pegar reciclagem. Aí no dia em que ela me viu, ela quase chorou." Ou seja, elemento constitutivo do discurso cristão, a solidariedade comparece como forma de mitigar os problemas sociais sem, contudo, alteração do meio de produção capitalista.

\section{Considerações finais}

Longe de ser um espaço estático, a cidade mostra(-se) o seu real: está em processo de mudança, em processo de significação, sempre provisória. Nesse processo, moradores (estabelecidos e outsiders) e cidade vão adquirindo novos sentidos, diferentes facetas...e isso se dá no espaço simbólico e material da polis. É nele que os sujeitos vão se constituindo, se reiventando, criando formas de significar e significar-se. Daí a afirmação de que a cidade não é estática - aliás, tanto a cidade quanto seus moradores mostram-se em movimento.

A resistência ao outro se deu de ambos os lados, do estabelecido em relação ao outsider e vice-versa. No caso específico dos outsiders, trata-se de sujeitos cujos corpos não são dóceis, ou seja, são avessos à docilização. As festas, os trajes, a linguagem, os costumes que trazem em sua bagagem etc. são um índice de resistência à tentativa castradora (procustiana) do estabelecido - pelo menos de uma parte dos moradores. 
A partir dos recortes apresentados, podemos afirmar que tanto o primeiro grupo quanto o segundo sofrem deslocamentos identificatórios importantes, ou seja, os sujeitos aí envolvidos, ao passarem a con-viver no mesmo espaço simbólico da cidade, entram em um processo de (des)construção de seu olhar. Assim, a partir do acontecimento discursivo “implantação de um campus universitário", não são mais os mesmos: nem a cidade, nem estabelecidos e outsiders. Em síntese e bem ao gosto do pensamento heraclitiano: nem a cidade é a mesma, nem tampouco seus moradores.

A partir da implantação de um campus universitário e, por conseguinte, da chegada de novos moradores de outros lugares - não somente de São Paulo como também de outros estados brasileiros para nele estudarem -, a cidade de CMA transforma-se em um espaço que passa a engendrar um novo processo não só de construção social como, também, de construção identitária, produzindo efeitos importantes nas relações discursivas entre os sujeitos envolvidos. Nesse processo vemos o real da cidade irromper: a cidade como local de (des)encontro entre estranhos. A esse respeito, vale dizer que aquele que é considerado 'estranho' (o de fora, o outro, a alteridade) também estranha o outro com o qual passa a conviver (os hospedeiros, os estabelecidos). Levando em conta o contexto de produção de nosso corpus, todos são estranhos buscando, cada qual a seu modo, estabilização de sentidos e de suas identidades ilusoriamente estabelecidas 13. Nessa relação com o outro, ninguém (estabelecidos e outsiders) sai ileso: todos são, de alguma forma, afetados inconsciente e ideologicamente.

Vimos que o discurso da consciência social aparece tanto na fala de parte dos estabelecidos quanto na dos outsiders, o que nos leva a considerar que a relação nem sempre é de oposição rígida (antítese) entre os sujeitos aí em questão. O que vemos é que as formas de ser dos outsiders têm constituído os estabelecidos e vice-versa, gerando uma síntese consequente, de modo a permitir relações de convivência e afetos.

Assim, apesar da tentativa de segregação se dar, em grande parte, inconscientemente, há uma brecha para possíveis mudanças de posição, o que permite um espaço de convívio e de relações entre eu-outro no espaço material da cidade, ainda que tal convívio seja atravessado por embates, contradições e/ou identificações de toda a ordem. 


\section{Bibliografia}

BOBblio, N. Política. In: METTEUCCI, N. PASQUINO, G. Dicionário de Política. Tradução de Carmen C. Varrialle. 6 ${ }^{\text {a }}$ Edição. Brasília: Editora da Universidade de Brasília, 1998.

CORACINI, M. J. A celebração do outro. Arquivo, memória e identidade: línguas materna e estrangeira. Campinas, SP: Mercado de Letras, 2007.

CORACINI, M. J. (Org.) Identidade e discurso: desconstruindo identidades. Campinas: Editora da UNICAMP; Chapecó: Argos Editora Universitária, 2003.

DERRIDA, Jacques. A escritura e a diferença; $3^{\text {a }}$ Ed. São Paulo: Ed. Perspectiva. 2002. Tradução: Maria Beatriz Marques Nizza da Silva, 249 p. Coleção Debates.

DERRIDA, Jacques. O monolinguismo do outro: ou a prótese de origem. Trad. Fernanda Bernardo. Porto: Campo das Letras, 1996.

DERRIDA, J [1972]. Posições. Trad. de Maria Margarida C. C. Barahona. Lisboa: Plátano, 1975.

ELIAS, N.; SCOTSON, J. L. Os estabelecidos e os outsiders: sociologia das relações de poder a partir de uma pequena comunidade. Rio de Janeiro: Jorge Jahar, 2000.

FOUCAULT, M. A ordem do discurso. São Paulo: Loyola, 1996.

FREUD, S. [1929] O mal-estar na civilização (Edição Standard Brasileira das Obras Psicológicas Completas de Sigmund Freud, Vol. 21). Rio de Janeiro: Imago, 1996.

FREUD, S. [1919]. O estranho. Obras completas, ESB, v. XVII. Rio de Janeiro: Imago, 1996.

HAROCHE. C. "Modèles de comportement et types d'aspirations dans les mouvements de jeunesse em Allemagne (1918/1933)", in Esprit de Corps, Guglielmi et alii (org), 2005.

KRISTEVA, Julia. Estrangeiros para nós mesmos. Rio de Janeiro: Rocco, 1994.

MARTINI, A. e COELHO JR., N. E. Novas notas sobre "O estranho". In: Tempo Psicanalítico: Rio de Janeiro, V. 42.2, p. 371-402, 2010.

MATTEI, J. F. A barbárie interior. Ensaio sobre o i-mundo moderno. Tradução de Isabel Maria Loureiro. São Paulo: Editora UNESP, 2002. 363 p.

MOTA, I. O.; PEREIRA, A.; NIERO, L. P. Cursinho popular Carolina Maria de Jesus da UFSCar Lagoa do Sino: sujeito, sentido e imaginário. Porto Velho (RO): Revista Igarapé, v.11, n.1, p. 83-96, 2018.

ORLANDI, E. P. Discurso em Análise: sujeito, sentido e ideologia. $2^{\mathrm{a}}$ edição. Campinas, SP: Editora Pontes, 2016.

ORLANDI, E. P. A contrapelo: incursão teórica na tecnologia - discurso eletrônico, escola, cidade. $R U A, 16(2), 6-17,2015$.

ORLANDI, E. P. A casa e a rua: uma relação política e social. Revista Educação Realidade, Porto Alegre, v. 36, n 3, p. 693-703, set./dez. 2011.

ORLANDI, E. P. Discurso e texto: formulação e circulação dos sentidos. Campinas, SP: Pontes, 2001.

ORLANDI, E. P. Análise de Discurso, princípios e procedimentos. Campinas, SP: Pontes, 1999. 
PÊCHEUX, M. [1983]. O discurso: estrutura ou acontecimento? Tradução de Eni P. Orlandi. Campinas, SP: Pontes, 1990, 68 p.

PÊCHEUX, M. “Análise Automática do Discurso.” In: GADET F.; HAK, T. (Orgs.) (1990) Por uma Análise Automática do Discurso: uma introdução à obra de Michel Pêcheux. Trad. de Eni P. Orlandi. Campinas: Unicamp, 1969.

ROLNIK, Raquel. O que é cidade? São Paulo: Brasiliense, 1988.

SAFATLE, V. Circuito dos Afetos: Corpos políticos, Desamparo, Fim do Indivíduo. 2 ed. rev.; 2. Reimp. Belo Horizonte: Autêntica Editora, 2016.

Data de Recebimento: 27/02/2020

Data de Aprovação: 14/05/2020 


\section{Para citar essa obra:}

MOTA, Ilka de Oliveira. Relações entre sujeitos em Campina do Monte Alegre após a implantação da UFSCar In: RUA [online]. Volume 26, número 1 - Ahead of print - e-ISSN 2179-9911 -jun./2020. Consultada no Portal Labeurb - Revista do Laboratório de Estudos Urbanos do Núcleo de Desenvolvimento da Criatividade.

http://www.labeurb.unicamp.br/rua/

Capa: Imagem do município de Campina do Monte Alegre, estado de São Paulo, Brasil. Disponível em: https://images.app.goo.gl/ros3JgrnKGe42Px39

Laboratório de Estudos Urbanos - LABEURB

Núcleo de Desenvolvimento da Criatividade - NUDECRI

Universidade Estadual de Campinas - UNICAMP

http://www.labeurb.unicamp.br/

Endereço:

LABEURB - LABORATÓRIO DE ESTUDOS URBANOS

UNICAMP/COCEN / NUDECRI

CAIXA POSTAL 6166

Campinas/SP - Brasil

CEP 13083-892

Fone/ Fax: (19) 3521-7900

Contato: http://www.labeurb.unicamp.br/contato 